\title{
Acaricidal and insecticidal properties of Coriandrum sativum oils and their major constituents extracted by three different methods against stored product pests
}

\author{
Myung-Ji Lee ${ }^{1} \cdot$ Sung-Eun Lee ${ }^{2}$ Min-Seung Kang ${ }^{1}$ • \\ Bueyong Park $^{3} \cdot$ Sang-Guei Lee ${ }^{3} \cdot$ Hoi-Seon Lee ${ }^{1}$
}

Received: 15 May 2018/Accepted: 28 May 2018/Published online: 25 June 2018

(C) The Korean Society for Applied Biological Chemistry 2018

\begin{abstract}
Essential oils of Coriandrum sativum were extracted by three different methods, including steam distillation (SDE), solvent (SE) and supercritical fluid extraction (SFE), to determine their acaricidal and insecticidal properties against Plodia interpunctella, Sitotroga cerealella and Tyrophagus putrescentiae. The fumigant bioassay against $P$. interpunctella, $S$. cerealella and $T$. putrescentiae revealed the strongest activity $\left(\mathrm{LD}_{50} 9.38\right.$, 18.76 and $4.19 \mu \mathrm{g} / \mathrm{cm}^{3}$ ) of oil obtained via SDE, followed by extraction via $\mathrm{SE}\left(\mathrm{LD}_{50}>75.20,21.11\right.$, and $>75.20$ $\left.\mu \mathrm{g} / \mathrm{cm}^{3}\right)$ and SFE $\left(\mathrm{LD}_{50}>75.20,27.36\right.$, and $>75.20 \mu \mathrm{g} /$ $\mathrm{cm}^{3}$ ). The contact bioassay against $T$. putrescentiae revealed the most potent activities of oil obtained via SDE $\left(\mathrm{LD}_{50} 19.29 \mu \mathrm{g} / \mathrm{cm}^{2}\right.$ ), followed by oil via SE and SFE. The chemical composition of $C$. sativum oils obtained by SDE, $\mathrm{HE}$ and SFE was analyzed by GC-MS. The $C$. sativum oil obtained by SDE contained linalool $(66.80 \%)$ compared with oils obtained by SE and SFE (70.67-70.80\%). However, camphor $(6.46 \%)$ was detected in SDE but not in the other two extracts. Based on the $\mathrm{LD}_{50}$ values of six major
\end{abstract}

Myung-Ji Lee and Sung-Eun Lee as first authors have contributed equally to this study.

Sang-Guei Lee

sglee@korea.kr

Hoi-Seon Lee

hoiseon@jbnu.ac.kr

1 Department of Bioenvironmental Chemistry, Chonbuk National University, Jeonju 54896, Republic of Korea

2 School of Applied Biosciences, Kyungpook National University, Daegu 41566, Republic of Korea

3 Crop Protection Division, Department of Crop Life Safety, National Institute of Agricultural Science, Wanju 55365, Republic of Korea compounds derived from the three $C$. sativum oils against $P$. interpunctella, S. cerealella and T. putresceentiae, camphor was considered the most active $(2.32,19.31$ and $3.24 \mu \mathrm{g} / \mathrm{cm}^{3}$, respectively) insecticide. The three values were about real camphor concentration in the oil via SDE. These results indicate that camphor contributes to the acaricidal and insecticidal activities of oil extracted via SDE of $C$. sativum seeds.

Keywords Acaricidal activity · Coriandrum sativum . Extraction method - Insecticidal activity $\cdot$ Plodia interpunctella $\cdot$ Sitotroga cerealella $\cdot$ Tyrophagus putresceentiae

\section{Introduction}

Agricultural products and stored harvest grains incur substantial losses and damage because of insect pests $[1,2]$. Plodia interpunctella, Sitotroga cerealella and Tyrophagus putrescentiae are distributed globally and are serious economic pests infesting stored products such as grains, flours, feeds, dried nuts and fruits [3-5]. The Indian meal moth, $P$. interpunctella, continuously produces silken web on the food surface. The food products contaminated with $P$. interpunctella are covered by their silken web [3]. The $S$. cerealella larvae invade grains and complete their larval and pupal stages within the grains. This pest feeding on the stored grain decreases its weight and nutritional value [4]. $T$. putrescentiae is a major species commonly contaminating stored products. Furthermore, these mites disseminate toxic fungi and induce allergic reactions among workers engaged in agriculture and food industries [5, 6]. 
Management of insect pests infesting stored products is generally accomplished via application of various chemical insecticides. However, chemical insecticides may be harmful to humans and result in outbreaks of environmental contamination, toxic residues and resistance. Therefore, safe insecticides are needed to decrease the adverse effects associated with the use of stored foods $[1,2]$. Essential oils and plant-derived products exhibiting acaricidal and insecticidal effects represent potential pest control agents $[2,7,8]$. The essential oils or plant extracts are generally obtained by various extraction methods such as hydrodistillation, steam distillation, solvent and supercritical fluid methods [8]. Variations in the chemical composition of essential oils have been observed depending on not only the plant part used in the extraction, and other local conditions, but also the various extraction methods [8-10]. Therefore, extraction methods play an important role in the isolation of bioactive compounds from plant extracts [11].

Coriandrum sativum (Coriander) is distributed in the Mediterranean region and belongs to family Apiaceae [12]. The medicinal properties of $C$. sativum have been exploited in the pharmaceutical industry against rheumatism and indigestion [13]. Furthermore, the C. sativum extract and essential oils have been used as a flavoring in food products and beauty industry $[14,15]$. A wide range of therapeutic effects including antimicrobial, antioxidant and insecticidal properties of the essential oil of $C$. sativum seeds have been reported [16]. This study was carried out to assess the acaricidal and insecticidal activities of the essential oil and its aromatic constituents derived from $C$. sativum seeds using the three extraction methods.

\section{Materials and methods}

\section{Chemicals and plant material preparation}

Camphor, geranyl acetate, linalool, $\alpha$-pinene and terpinene derived from the three extracted oils were purchased from Sigma-Aldrich (St. Louis, MO, USA), while limonene was obtained from Tokyo Chemical Industry (Tokyo, Japan). All chemicals are analytical grade. The Coriandrum sativum seeds $(5 \mathrm{~kg})$ were bought from a herbal market (Jeonju, South Korea). The C. sativum fresh seeds (200 g) were washed and machine-ground to a powder prior to steam distillation extraction (SDE), solvent extraction (SE) and supercritical fluid extraction (SFE).

\section{Steam distillation extraction (SDE)}

The $C$. sativum seeds were processed at the Jeollanam-do Institute of Natural Resources Research (Jangheung,
Korea) by steam distillation for $4 \mathrm{~h}$ at $100{ }^{\circ} \mathrm{C}$ using an essential oil extractor device (EM-250, Micro, Korea). The extraction was performed by a steam extractor containing the seeds and distilled water. As the water heated, the water vapor was produced by steam extractor and the steam passed to the condenser and collected on the receiving flask.

\section{Solvent extraction (SE)}

Dried $C$. sativum seeds were pulverized and placed in a $5-\mathrm{L}$ Erlenmeyer flask with $100 \%$ hexane (Hexane, $1500 \mathrm{~mL} \times 2$ ). The extraction was performed on a shaking incubator at $200 \mathrm{rpm}$ and $25{ }^{\circ} \mathrm{C}$ for $48 \mathrm{~h}$. The extract of $C$. sativum seeds was filtered and concentrated using a rotary vacuum evaporator at $35^{\circ} \mathrm{C}$.

\section{Supercritical fluid $\left(\mathrm{CO}_{2}\right)$ extraction (SFE)}

The $C$. sativum seeds were ground and powdered at the Jeollanam-do Nano Bio Research Center (Jangsung, Korea) using a SCFE-0500 supercritical fluid extractor (Ilshin autoclave, Daejeon, Korea). Extraction and separation were conducted at pressures of 400 and 40 bar and temperatures of 50 and $40{ }^{\circ} \mathrm{C}$ for $120 \mathrm{~min}$, respectively. The supercritical $\mathrm{CO}_{2}$ flow rate was approximately $60 \mathrm{~mL} /$ $\min$.

\section{Mite and insect colonies}

T. putrescentiae were reared on artificial diet including protein $(46.0 \%)$, fiber $(4.0 \%)$, phosphate $(2.0 \%)$, lipid $(3.0 \%)$ and calcium $(1.1 \%)$ and stored in plastic containers $(15 \times 12 \times 6 \mathrm{~cm})$ under controlled conditions (26 $\pm 1{ }^{\circ} \mathrm{C}, 70 \pm 5 \%$ relative humidity). The artificial diet was purchased from Korea Special Feed Meal Co. (Jeonju, Korea). P. interpunctella (larvae and adults) and S. cerealella (adults) were obtained from the insect-rearing room of a laboratory at $27 \pm 1{ }^{\circ} \mathrm{C}$ and $40-60 \%$ relative humidity under darkness. They were reared on rice bran and barley in an acrylic growth cage $\left(40 \times 40 \times 40 \mathrm{~cm}^{3}\right)$ [5].

\section{Chemical analysis of $C$. sativum seed oil}

The chemical composition of the three essential oils of $C$. sativum seeds was determined using GC-MS. The GC-MS analysis of the volatile constituents present in the three oils was performed using an Agilent HP-6890 gas chromatography coupled to an Agilent 5973IV mass spectrometer (Agilent Technology, Santa Clare, CA, USA) with helium as the carrier gas on a DB-5 column $(0.25 \mathrm{~mm}$ i.d. $\times 30$ $\mathrm{mL} \times 0.25 \mu \mathrm{m}$ film thickness) at a flow rate of $0.8 \mathrm{~mL} /$ min. In all cases, the analytic conditions were as follows: 
ion source temperature, $220^{\circ} \mathrm{C}$; injector temperature, $210{ }^{\circ} \mathrm{C}$; sample temperature $20^{\circ} \mathrm{C}$ for $15 \mathrm{~min}$; and programmed to increase by $2{ }^{\circ} \mathrm{C} / \mathrm{min}-220{ }^{\circ} \mathrm{C}$. The $\mathrm{MS}$ detector operated in the electron ionization mode at $70 \mathrm{eV}$.

\section{Bioassays}

The acaricidal activities of the essential oils of $C$. sativum seeds and all compounds against $T$. putrescentiae were evaluated in contact and fumigant bioassays, as modified by Yang et al. [6]. In the contact bioassay, the filter papers were moistened evenly with $50 \mu \mathrm{L}$ of $C$. sativum oil and its constituents added at different concentrations (75.20-1.00 $\mu \mathrm{g} / \mathrm{cm}^{3}$ ). The base formulation, methanol, was used as a solvent and negative control. After drying for $10 \mathrm{~min}$, the treated filter paper was placed at the bottom of a Petri dish (35 $\mathrm{mm}$ diameter) followed by addition of 20 mites and sealed with parafilm. In the fumigant bioassay, the essential oils and compounds were dissolved in acetone in order to obtain $75.20-1.00 \mu \mathrm{g} / \mathrm{cm}^{3}$ concentrations. The fabric disks ( $8 \mathrm{~mm}$ diameter and $1 \mathrm{~mm}$ thick) were treated with test solutions $(10 \mu \mathrm{L})$ and dried for $10 \mathrm{~min}$. The fabric disks were placed at the top of a microtube. Twenty adult mites were added to the microtubes. Acetone was used as the negative control. Treatments in the contact and fumigant bioassays were repeated three times at $26 \pm 1{ }^{\circ} \mathrm{C}$ for $24 \mathrm{~h}$.

Contact and fumigant bioassays were used to evaluate the insecticidal toxicity of the essential oils and their constituents against $P$. interpunctella and $S$. cerealella. Using a contact bioassay, different doses (75.2-1.0 $\mu \mathrm{g} /$ $\mathrm{cm}^{2}$ ) of each sample were suspended in methanol and applied to filter paper. The filter paper was placed at the bottom of a Petri dish after solvent evaporation for $10 \mathrm{~min}$. Twenty $P$. interpunctella larvae were moved in the Petri dish, and the lid was sealed. To determine the fumigation of the samples against adults of $P$. interpunctella and $S$. cerealella, the filter paper was treated with an appropriate concentration $\left(75.2-1.0 \mu \mathrm{g} / \mathrm{cm}^{3}\right)$ of the test samples in methanol. The impregnated filter paper (90 $\mathrm{mm}$ diameter) was then placed inside the lids of a glass jar $(90 \mathrm{~mm}$ diameter, $80 \mathrm{~mm}$ height). In order to prevent evaporation of the tested samples, the lids were sealed. Acetone was used to treat the control jars. Twenty adults were released individually at the bottom of the glass jar and exposed for $48 \mathrm{~h}$. These jars were maintained at $27 \pm 1{ }^{\circ} \mathrm{C}$ and $40-60 \%$ relative humidity for $48 \mathrm{~h}$. After the experiment, the mortality of adults was recorded after treatment. All experimental procedures were performed in triplicate.

\section{Statistical method}

Lethal doses $\left(\mathrm{LD}_{50}\right.$ and $\left.\mathrm{LD}_{90}\right)$ of the three essential oils and their major constituents were calculated by probit analysis using SPSS version 12.0 for Windows (SPSS Inc., Chicago, IL, USA). The $\mathrm{LD}_{50}$ and $\mathrm{LD}_{90}$ values of the tested samples considered vary significantly from one another when $95 \%$ confidence limits did not overlap.

\section{Results and discussion}

The acaricidal and insecticidal activities of the three $C$. sativum oils extracted by SDE, SE and SFE against $T$. putrescentiae, $P$. interpunctella and $S$. cerealella were tested using contact and fumigant bioassays (Table 1). In the contact and fumigant bioassays against adults of $T$. putrescentiae, the most active oils were SDE oil (19.29 and $\left.4.19 \mu \mathrm{g} / \mathrm{cm}^{3}\right)$, followed by SE oil $\left(29.25\right.$ and $\left.9.38 \mu \mathrm{g} / \mathrm{cm}^{3}\right)$ and SFE oils $\left(31.57\right.$ and $\left.>75.20 \mu \mathrm{g} / \mathrm{cm}^{3}\right)$, respectively. In the contact and fumigant bioassays against the larvae of $P$. interpunctella, none of the SED, SE and SFE oils exhibited insecticidal activity, while the SED oil showed only insecticidal activity $\left(\mathrm{LD}_{50} 9.38 \mu \mathrm{g} / \mathrm{cm}^{3}\right)$ against $P$. interpunctella adults in the fumigant bioassay. Based on the $\mathrm{LD}_{50}$ values of three $C$. sativum oils against $S$. cerealella in the fumigant bioassay, the most active oil was SDE oil $\left(\mathrm{LD}_{50} 18.76 \mu \mathrm{g} / \mathrm{cm}^{3}\right)$, followed by SE oil $\left(\mathrm{LD}_{50} 21.11 \mu \mathrm{g} /\right.$ $\left.\mathrm{cm}^{3}\right)$ and SFE oil $\left(\mathrm{LD}_{50} 27.36 \mu \mathrm{g} / \mathrm{cm}^{3}\right)$. At a dosage of $0.08 \mu \mathrm{g} / \mathrm{mL}$ in the fumigant bioassay, treatment with the essential oil of $C$. sativum resulted in $100 \%$ mortality of larvae, pupae and adults of Tribolium castaneum [12]. In the laboratory studies of Zoubiri et al. [13], the essential oil derived from $C$. sativum at an atmospheric concentration of $10 \mu \mathrm{L} / \mathrm{L}$ caused $70 \%$ mortality of Sitophilus granarius after $120 \mathrm{~h}$. In this regard, many studies reported that the acaricidal and insecticidal activities of $C$. sativum may be due to contact and fumigant bioassays against stored product pests. Furthermore, our studies showed differences in the degree of acaricidal and insecticidal activity of $C$. sativum oils against $P$. interpunctella, S. cerealella and $T$. putrescentiae. Similar studies suggested that the Tanacetum parthenium oil extracted by hydrodistillation against Spodoptera littoralis was more active $\left(\mathrm{LD}_{50} 0.05 \mu \mathrm{L} / \mathrm{lar}\right.$ vae, and $\mathrm{LD}_{90}, 0.18 \mu \mathrm{L} /$ larvae, respectively) than the other oil extracted by SFE [16]. Pavela et al. [17] found that the Satureja hortenisis oil extracted by hydrodistillation and supercritical extractions (extracted with pure $\mathrm{CO}_{2}$ at $12 \mathrm{MPa}$ and $50{ }^{\circ} \mathrm{C}$ ) exhibited the most insecticidal activities against Leptinotarsa decemlineata, Spodoptera littoralis, Musca domestica and Culex quinquefasciatus. Chiasson et al. [10] demonstrated that among the essential oils of Artemisia absinthium and Tanacetum vulgare 


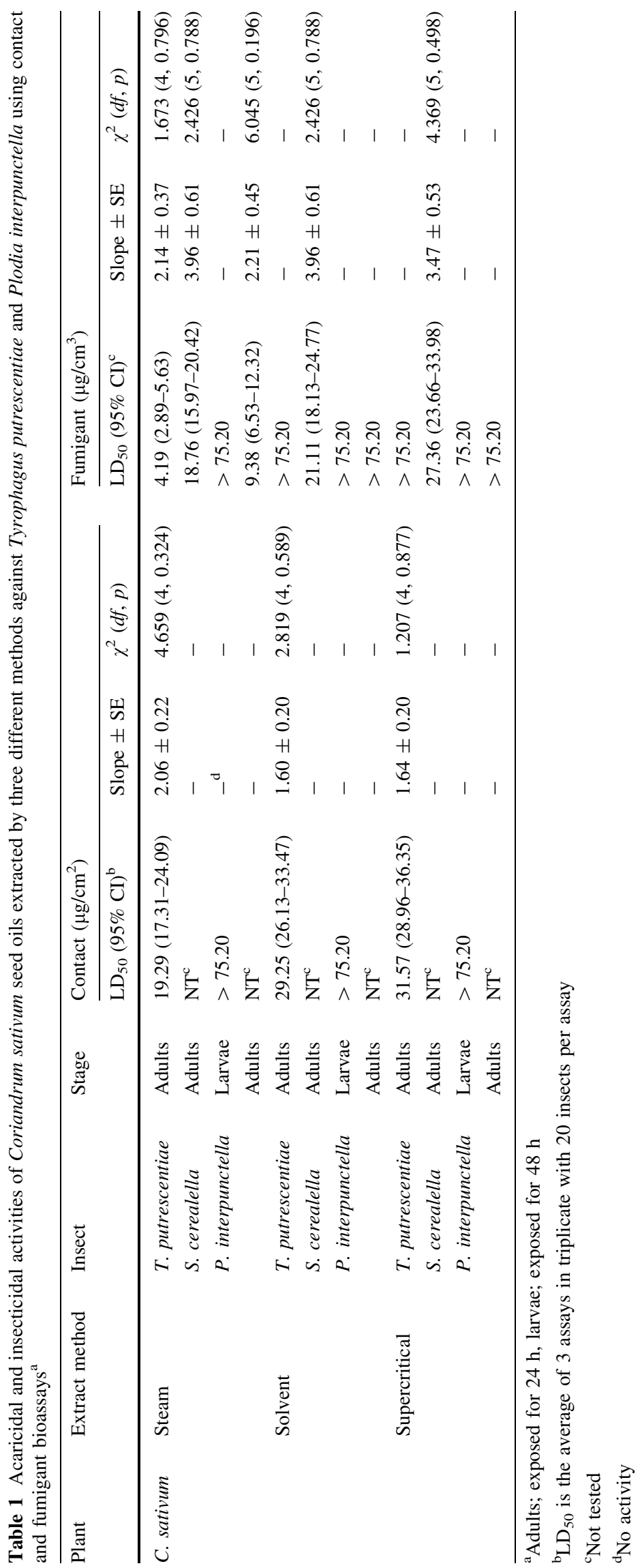


Table 2 GC-MS analyses of essential oils derived from C. sativum seeds via three different extraction methods

\begin{tabular}{|c|c|c|c|c|c|c|}
\hline \multirow[t]{2}{*}{ No. } & \multirow[t]{2}{*}{ Compounds } & \multirow[t]{2}{*}{$\mathrm{RI}^{\mathrm{a}}$} & \multicolumn{4}{|l|}{ Relative amount (\%) } \\
\hline & & & Steam distillation extraction & Hexane extraction & \multicolumn{2}{|c|}{ Supercritical fluid extraction } \\
\hline 1 & $\alpha$-Pinene & 939 & 7.79 & 3.05 & 9.84 & \\
\hline 2 & Camphene & 953 & 1.51 & $-{ }^{\mathrm{b}}$ & - & \\
\hline 3 & Myrcene & 992 & 1.01 & - & - & \\
\hline 4 & Cymene & 1027 & 2.94 & - & - & \\
\hline 5 & Limonene & 1033 & 3.79 & - & - & \\
\hline 6 & Terpinene & 1074 & 3.97 & - & - & \\
\hline 7 & Terpinolene & 1084 & 1.15 & - & - & \\
\hline 8 & Linalool & 1100 & 66.80 & 70.67 & 70.80 & \\
\hline 9 & Camphor & 1139 & 6.46 & - & - & \\
\hline 10 & $\alpha$-Terpineol & 1195 & 0.37 & - & - & \\
\hline 11 & Linalool oxide & 1212 & 0.50 & - & - & \\
\hline 12 & Citronellyl acetate & 1357 & - & 0.79 & - & \\
\hline 13 & Geranyl acetate & 1382 & 3.17 & 24.31 & 18.40 & \\
\hline 14 & Myristic acid & 1720 & - & - & 0.96 & \\
\hline \multicolumn{7}{|c|}{ Major compound groups } \\
\hline \multicolumn{3}{|c|}{ Acid } & - & \multicolumn{2}{|l|}{-} & 0.96 \\
\hline \multicolumn{3}{|c|}{ Monoterpene alcohol } & 67.17 & \multicolumn{2}{|l|}{70.67} & 70.80 \\
\hline \multicolumn{3}{|c|}{ Monoterpene esters } & 3.17 & \multicolumn{2}{|l|}{25.10} & 18.40 \\
\hline \multicolumn{3}{|c|}{ Monoterpene ether } & 0.50 & \multicolumn{2}{|l|}{-} & - \\
\hline \multicolumn{3}{|c|}{ Monoterpene ketone } & 6.46 & \multicolumn{2}{|l|}{-} & - \\
\hline \multicolumn{3}{|c|}{ Monoterpene hydrocarbons } & 22.16 & \multicolumn{2}{|l|}{3.05} & 9.84 \\
\hline \multicolumn{3}{|c|}{ Total $(\%)$} & 99.46 & \multicolumn{2}{|l|}{98.82} & 100 \\
\hline \multicolumn{3}{|c|}{ Yield (\%) } & 0.29 & 2.22 & & 3.43 \\
\hline
\end{tabular}

${ }^{a} \mathrm{RI}$ : The retention indices were determined on DB-5 column

b-: Not detection

extracted by microwave-assisted process, distillation in water and direct steam, the oil obtained via direct steam distillation was the most toxic against Tetranychus urticae. These studies demonstrated that the acaricidal and insecticidal activities against various types of insects showed significant differences with methods of plant extraction. Therefore, our results indicate that the $C$. sativum oil obtained by SED was more effective in controlling the pests infesting stored products than the oils obtained by two other extraction methods.

The relative amounts (\%) of $C$. sativum oil components obtained by the three extraction methods vary according to the results of GC-MS (Table 2). Essential oils derived from the seeds of $C$. sativum isolated by SDE, SE and SFE showed a yield of $0.25,2.22$ and $3.43 \%$, respectively. Fourteen compounds in the $C$. sativum oils have been identified and comprise mainly monoterpenoids: 1 acid (myristic acid), 2 monoterpene alcohols (linalool, $\alpha$-terpineol), 1 monoterpene ether (linalool oxide), 2 monoterpene ester (citronellyl acetate, geranyl acetate), 1 monoterpene ketone (camphor) and 7 monoterpene hydrocarbons $(\alpha-$ pinene, camphene, myrcene, cymene, limonene, terpinene and terpinolene). The main components of the $C$. sativum oil obtained by SDE were linalool $(66.80 \%), \alpha$-pinene (7.79\%), camphor $(6.46 \%)$, terpinene $(3.97 \%)$, limonene (3.79\%), geranyl acetate $(3.17 \%)$, cymene $(2.94 \%)$, camphene $(1.51 \%)$, myrcene $(1.01 \%)$, linalool oxide $(0.50 \%)$ and terpineol $(0.37 \%)$. The major composition of the $C$. sativum oil obtained by SE included linalool (70.67\%), geranyl acetate $(24.31 \%), \alpha$-pinene $(3.05 \%)$ and citronellyl acetate $(0.79 \%)$. The main constituents of the C. sativum oil obtained by SFE were linalool $(70.80 \%)$, geranyl acetate $(18.40 \%), \alpha$-pinene $(9.84 \%)$ and myristic acid $(0.96 \%)$. In the $C$. sativum oils, linalool was the major component obtained with all the three extraction methods. Our result was consistent with previous studies that reported linalool as the major compound occurring in the C. sativum oil [13, 15, 18]. Benelli et al. [19] demonstrated 
Table 3 Acaricidal and insecticidal activities of major components derived from $C$. sativum seed oil against $T$. putrescentiae and $P$. interpunctella in the contact bioassay ${ }^{\mathrm{a}}$

\begin{tabular}{|c|c|c|c|c|c|c|}
\hline \multirow[t]{2}{*}{ Compounds } & \multirow[t]{2}{*}{ Insects } & \multirow[t]{2}{*}{ Stage } & \multicolumn{4}{|l|}{ Contact $\left(\mu \mathrm{g} / \mathrm{cm}^{2}\right)$} \\
\hline & & & $\mathrm{LD}_{50}(95 \% \mathrm{CI})^{\mathrm{b}}$ & $\mathrm{LD}_{90}(95 \% \mathrm{CI})$ & Slope \pm SE & $\chi^{2}(d f, p)$ \\
\hline \multirow[t]{2}{*}{$\alpha$-Pinene } & T. putrescentiae & Adults & $>75.20$ & $-^{c}$ & - & - \\
\hline & P. interpunctella & Larvae & $>75.20$ & - & - & - \\
\hline \multirow[t]{2}{*}{ Limonene } & T. putrescentiae & Adults & 22.87 (18.79-27.93) & $60.70(46.14-93.74)$ & $3.02 \pm 0.42$ & $2.704(5,0.746)$ \\
\hline & P. interpunctella & Larvae & $>75.20$ & - & - & - \\
\hline \multirow[t]{2}{*}{ Terpinene } & T. putrescentiae & Adults & $>75.20$ & - & - & - \\
\hline & P. interpunctella & Larvae & $>75.20$ & - & - & - \\
\hline \multirow[t]{2}{*}{ Linalool } & T. putrescentiae & Adults & $4.39(3.59-5.41)$ & $11.67(8.73-19.01)$ & $3.02 \pm 0.45$ & $2.126(5,0.831)$ \\
\hline & P. interpunctella & Larvae & $>75.20$ & - & - & - \\
\hline \multirow[t]{2}{*}{ Camphor } & T. putrescentiae & Adults & $2.81(2.30-3.44)$ & $7.64(5.75-12.23)$ & $2.95 \pm 0.44$ & $3.010(5,0.698)$ \\
\hline & P. interpunctella & Larvae & $>75.20$ & - & - & - \\
\hline \multirow[t]{2}{*}{ Geranyl acetate } & T. putrescentiae & Adults & $>75.20$ & - & - & - \\
\hline & P. interpunctella & Larvae & $>75.20$ & - & - & - \\
\hline
\end{tabular}

${ }^{a}$ Adults; exposed for $24 \mathrm{~h}$, larvae; exposed for $48 \mathrm{~h}$

${ }^{\mathrm{b}} \mathrm{LD}_{50}$ is the average of 3 assays in triplicate with 20 insects per assay

${ }^{\mathrm{c}}$ No activity

the presence of linalool $(83.60 \%)$ in the $C$. sativum oil. The main constituents of the $C$. sativum oil obtained by SDE, SE and SFE are mostly similar, whereas the identified compounds apparently varied. The $C$. sativum oil obtained by SDE contains camphor (6.46\%), which is also the main acaricidal and insecticidal ingredient in the $C$. sativum oil $[20,21]$. Thus, the highest percentage of active acaricidal and insecticidal ingredients in the C. sativum oil extracted by SDE containing linalool together with camphor was obtained.

The content of camphene, citronellyl acetate, cymene, linalool oxide, myrcene, myristic acid, terpinolene and $\alpha$ terpineol in the $C$. sativum oils extracted by SDE, SE and SFE was relatively small (0.50-2.94\%), suggesting limited toxicity. Therefore, the acaricidal and insecticidal activities of six compounds (camphor, geranyl acetate, limonene, linalool, $\alpha$-pinene and terpinene, constituting $3 \%$ of the total composition) derived from the $C$. sativum oils extracted by SDE, SE and SFE were determined using contact and fumigant bioassays against $P$. interpunctella (larvae and adults), S. cerealella (adults) and T. putrescentiae (adults) (Tables 3, 4). In the contact and fumigant actions against $T$. putrescentiae (Tables 3,4 ), the most toxic compound was camphor (2.81 and $\left.3.24 \mu \mathrm{g} / \mathrm{cm}^{3}\right)$, followed by linalool $\left(4.39\right.$ and $\left.5.49 \mu \mathrm{g} / \mathrm{cm}^{3}\right)$ and limonene (22.87 and $43.72 \mu \mathrm{g} / \mathrm{cm}^{3}$ ), respectively. Geranyl acetate, $\alpha$ pinene and terpinene against $T$. putrescentiae showed no acaricidal effect at the tested concentrations $(>75.20 \mu \mathrm{g} /$ $\mathrm{cm}^{2}$ and $\mu \mathrm{g} / \mathrm{cm}^{3}$ ). In the fumigant bioassay against $S$. cerealella (Table 4), the most toxic compound was linalool $\left(11.80 \mu \mathrm{g} / \mathrm{cm}^{3}\right)$, followed by camphor $\left(19.31 \mu \mathrm{g} / \mathrm{cm}^{3}\right)$ and terpinene $\left(30.49 \mu \mathrm{g} / \mathrm{cm}^{3}\right)$. Limonene, geranyl acetate and $\alpha$-pinene showed no insecticidal activity against $S$. cerealella $\left(>75.20 \mu \mathrm{g} / \mathrm{cm}^{3}\right)$ at the tested concentrations in the contact and fumigant bioassays. In the case of $P$. interpunctella larvae, none of the tested compounds showed any insecticidal activity in the contact and fumigant bioassays. Based on the $\mathrm{LD}_{50}$ against $P$. interpunctella adults in fumigant bioassay, the most toxic compound was camphor $\left(2.32 \mu \mathrm{g} / \mathrm{cm}^{3}\right)$, followed by terpinene $\left(4.62 \mu \mathrm{g} / \mathrm{cm}^{3}\right)$, while limonene, linalool, geranyl acetate and $\alpha$-pinene did not manifest insecticidal activity against $P$. interpunctella adults. In our study, among the six compounds tested, camphor (monoterpene ketone) was the most active against stored product insects tested. The higher potencies of SDE oil compared with SE and SFE oils were attributed to their chemical composition. Camphor constituted $6.46 \%$ of the oil composition obtained via SDE and was absent in the other two oils. Similar trends regarding acaricidal and insecticidal activities of camphor against various insect species have already been reported [21, 22]. Papachristos et al. [22] suggested that monoterpene ketones were generally more toxic than monoterpene alcohols, and both showed higher activity compared with monoterpene hydrocarbons. Therefore, the acaricidal and insecticidal activities may be related to the presence of camphor. Certain plant essential oils and plant-derived compounds may manifest either synergistic or antagonistic efficacy in 
Table 4 Acaricidal and insecticidal activities of major components derived from $C$. sativum seed oil against T. putrescentiae, S. cerealella and $P$. interpunctella in the fumigant bioassay ${ }^{\mathrm{a}}$

\begin{tabular}{|c|c|c|c|c|c|c|}
\hline \multirow[t]{2}{*}{ Compounds } & \multirow[t]{2}{*}{ Insect } & \multirow[t]{2}{*}{ Stage } & \multicolumn{4}{|l|}{ Fumigant $\left(\mu \mathrm{g} / \mathrm{cm}^{3}\right)$} \\
\hline & & & $\mathrm{LD}_{50}(95 \% \mathrm{CI})^{\mathrm{b}}$ & $\mathrm{LD}_{90}(95 \% \mathrm{CI})$ & Slope \pm SE & $\chi^{2}(d f, p)$ \\
\hline \multirow[t]{4}{*}{$\alpha$-Pinene } & T. putrescentiae & Adults & $>75.20$ & $-^{\mathrm{c}}$ & - & - \\
\hline & S. cerealella & Adults & $>75.20$ & - & - & - \\
\hline & P. interpunctella & Larvae & $>75.20$ & - & - & - \\
\hline & & Adults & $>75.20$ & - & - & - \\
\hline \multirow[t]{4}{*}{ Limonene } & T. putrescentiae & Adults & $43.72(36.96-51.44)$ & 95.75 (77.41-132.42) & $3.76 \pm 0.50$ & $4.169(5,0.527)$ \\
\hline & S. cerealella & Adults & $>75.20$ & - & - & - \\
\hline & P. interpunctella & Larvae & $>75.20$ & - & - & - \\
\hline & & Adults & $>75.20$ & - & - & - \\
\hline \multirow[t]{4}{*}{ Terpinene } & T. putrescentiae & Adults & $>75.20$ & - & - & - \\
\hline & S. cerealella & Adults & $30.49(24.91-35.92)$ & $65.82(53.25-95.00)$ & $3.83 \pm 0.65$ & $4.314(4,0.365)$ \\
\hline & P. interpunctella & Larvae & $>75.20$ & - & - & - \\
\hline & & Adults & $4.62(3.43-6.30)$ & $16.72(11.04-34.49)$ & $2.29 \pm 0.37$ & $4.140(4,0.387)$ \\
\hline \multirow[t]{4}{*}{ Linalool } & T. putrescentiae & Adults & $5.49(4.55-6.65)$ & $13.85(10.56-21.93)$ & $3.19 \pm 0.48$ & $1.194(5,0.945)$ \\
\hline & S. cerealella & Adults & $11.80(9.95-14.02)$ & $27.59(21.70-40.69)$ & $3.47 \pm 0.49$ & $2.372(5,0.796)$ \\
\hline & P. interpunctella & Larvae & $>75.20$ & - & - & - \\
\hline & & Adults & $>75.20$ & - & - & - \\
\hline \multirow[t]{4}{*}{ Camphor } & T. putrescentiae & Adults & $3.24(2.66-3.91)$ & $8.46(6.50-12.92)$ & $3.07 \pm 0.44$ & $3.078(5,0.688)$ \\
\hline & S. cerealella & Adults & $19.31(15.64-23.68)$ & $54.70(41.25-85.75)$ & $2.83 \pm 0.40$ & $4.151(5,0.528)$ \\
\hline & P. interpunctella & Larvae & $>75.20$ & - & - & - \\
\hline & & Adults & $2.32(1.73-3.03)$ & $8.43(5.89-15.17)$ & $2.28 \pm 0.34$ & $3.760(5,0.584)$ \\
\hline \multirow[t]{4}{*}{ Geranyl acetate } & T. putrescentiae & Adults & $>75.20$ & - & - & - \\
\hline & S. cerealella & Adults & $>75.20$ & - & - & - \\
\hline & P. interpunctella & Larvae & $>75.20$ & - & - & - \\
\hline & & Adults & $>75.20$ & - & - & - \\
\hline
\end{tabular}

${ }^{a}$ Adults; exposed for $24 \mathrm{~h}$, larvae; exposed for $48 \mathrm{~h}$

${ }^{\mathrm{b}} \mathrm{LD}_{50}$ is the average of 3 assays in triplicate with 20 insects per assay

${ }^{\mathrm{c}}$ No activity

terms of biological activity [10]. The toxicity of C. sativum oil is attributed to the composition of camphor and linalool and their combination.

In conclusion, the oils extracted from $C$. sativum seeds via SDE, SE and SFE, and their constituents represent potential acaricides and insecticides targeting $T$. putrescentiae, $P$. interpunctella and $S$. cerealella. Different extraction methods play an important role in extracting specific bioactive compounds from plants. Therefore, the choice of the extraction method dictates the type of bioactive chemicals desired.

Acknowledgments This work was carried out with the support of "Cooperative Research Program for Agriculture Science and Technology Development (Project title: Development of crop pest management techniques using the functional materials derived from Coriandrum sativum and Valeriana fauriei, Project No. PJ011983012018)" Rural Development Administration, Korea.

\section{References}

1. Park JH, Lee HS (2017) Phototactic behavioral response of agricultural insects and stored-product insects to light-emitting diodes (LEDs). Appl Biol Chem 60:137-144

2. Isman MB (2000) Plant essential oils for pest and disease management. Crop Prtect 19:603-608

3. Shojaaddini M, Moharramipour S, Sahaf B (2008) Fumigant toxicity of essential oil from Carum copticum against Indian meal moth, Plodia interpunctella. J Plant Prot Res 48:411-419

4. Fouad HA, Faroni LRDA, de Souza Tavares W, Ribeiro RC, de Sousa Freitas S, Zanuncio JC (2014) Botanical extracts of plants from the Brazilian Cerrado for the integrated management of Sitotroga cerealella (Lepidoptera: Gelechiidae) in stored grain. J Stored Prod Res 57:6-11

5. Jeon YJ, Lee SG, Lee HS (2017) Acaricidal and insecticidal activities of essential oils of Cinnamomum zeylanicum barks cultivated from France and India against Dermatophagoides spp., Tyrophagus putrescentiae and Ricania sp. Appl Biol Chem 60:259-264 
6. Yang JY, Lee HS (2012) Acaricidal activities of the active component of Lycopus lucidus oil and its derivatives against house dust and stored food mites (Arachnida: Acari). Pest Manage Sci 68:564-572

7. Kim MG, Lee HS (2016) Insecticidal toxicities of naphthoquinone and its structural derivatives. Appl Biol Chem 59:3-8

8. Bae IK, Kim K, Choi SD, Chang KS, Lee HS, Lee SE (2017) Mosquito larvicidal activities of naturally occurring compounds derived from Piper species. Appl Biol Chem 60:113-117

9. Reverchon E, Senatore F (1992) Isolation of rosemary oil: comparison between hydrodistillation and supercritical $\mathrm{CO}_{2}$ extraction. Flavour Frag J 7:227-230

10. Chiasson H, Bélanger A, Bostanian N, Vincent C, Poliquin A (2001) Acaricidal properties of Artemisia absinthium and Tanacetum vulgare (Asteraceae) essential oils obtained by three methods of extraction. J Econ Entomol 94:167-171

11. Azmir J, Zaidul ISM, Rahman MM, Sharif KM, Mohamed A, Sahena F, Omar AKM (2013) Techniques for extraction of bioactive compounds from plant materials: a review. J Food Eng 117:426-436

12. Islam MS, Hasan MM, Xiong W, Zhang SC, Lei CL (2009) Fumigant and repellent activities of essential oil from Coriandrum sativum (L.) (Apiaceae) against red flour beetle Tribolium castaneum (Herbst)(Coleoptera: Tenebrionidae). J Pest Sci 82:171-177

13. Zoubiri S, Baaliouamer A (2010) Essential oil composition of Coriandrum sativum seed cultivated in Algeria as food grains protectant. Food Chem 122:1226-1228

14. Lo Cantore P, Iacobellis NS, De Marco A, Capasso F, Senatore F (2004) Antibacterial activity of Coriandrum sativum L. and Foeniculum vulgare Miller var. vulgare (Miller) essential oils. J Agric Food Chem 52:7862-7866

15. López MD, Jordán MJ, Pascual-Villalobos MJ (2008) Toxic compounds in essential oils of coriander, caraway and basil active against stored rice pests. J Stored Prod Res 44:273-278
16. Pavela R, Sajfrtová M, Sovová H, Bárnet M, Karban J (2010) The insecticidal activity of Tanacetum parthenium (L.) Schultz Bip. extracts obtained by supercritical fluid extraction and hydrodistillation. Ind Crop Prod 31:449-454

17. Pavela R, Sajfrtová M, Sovová H, Bárnet M (2008) The insecticidal activity of Satureja hortensis L. extracts obtained by supercritical fluid extraction and traditional extraction techniques. Appl Entomol Zool 43:377-382

18. Kim J, Seo SM, Lee SG, Shin SC, Park IK (2008) Nematicidal activity of plant essential oils and components from coriander (Coriandrum sativum), oriental sweetgum (Liquidambar orientalis), and valerian (Valeriana wallichii) essential oils against pine wood nematode (Bursaphelenchus xylophilus). J Agric Food Chem 56:7316-7320

19. Benelli G, Flamini G, Fiore G, Cioni PL, Conti B (2013) Larvicidal and repellent activity of the essential oil of Coriandrum sativum L. (Apiaceae) fruits against the filariasis vector Aedes albopictus Skuse (Diptera: Culicidae). Parasitol Res 112:1155-1161

20. Jeon JH, Yang JY, Lee HS (2014) Evaluation of the acaricidal toxicities of camphor and its structural analogues against house dust mites by the impregnated fabric disc method. Pest Manag Sci 70:1030-1032

21. Chen HP, Yang K, You CX, Lei N, Sun RQ, Geng ZF, Deng ZW (2014) Chemical constituents and insecticidal activities of the essential oil of Cinnamomum camphora leaves against Lasioderma serricorne. J Serb Chem Soc 79:1213-1222

22. Papachristos DP, Karamanoli KI, Stamopoulos DC, MenkissogluSpiroudi U (2004) The relationship between the chemical composition of three essential oils and their insecticidal activity against Acanthoscelides obtectus (Say). Pest Manag Sci $60: 514-520$ 